\title{
Prevalence of Mental Disorder among the Client Visiting Outpatient Department in Karnali Academy of Health Science
}

\author{
Nirmala Kumari Pahadi*, Shandiya Chaulagain \\ School of Nursing and Midwifery, Karnali Academy of Health Science, Jumla, Nepal \\ Email: ^admire_niru@yahoo.com
}

How to cite this paper: Pahadi, N.K. and Chaulagain, S. (2020) Prevalence of Mental Disorder among the Client Visiting Outpatient Department in Karnali Academy of Health Science. Open Access Library Journal, 7: e6718.

https://doi.org/10.4236/oalib.1106718

Received: August 15, 2020

Accepted: December 7, 2020

Published: December 10, 2020

Copyright () 2020 by author(s) and Open Access Library Inc.

This work is licensed under the Creative Commons Attribution International License (CC BY 4.0).

http://creativecommons.org/licenses/by/4.0/

\begin{abstract}
Introduction: Mental illnesses are health conditions involving changes in emotion, thinking or behavior (or a combination of these). Mental illnesses are associated with distress and/or problems functioning in social, work or family activities. So the study was carried out to find the pattern of mental disorders of OPD patients in Karnali academy of health science. Method: This was a retrospective study conducted among the patients attending for OPD check up in Karnali Academy of Health Science (KAHS) in the department of psychiatric. The study was done from April 1, 2018 to March 31, 2020. Only mental disorders were included. Data were collected from the register of psychiatric OPD which were maintained in the medical department. Total number of sample taken was 944 in first year and 1685 in second year that is 2629 of all age group. Result: A total of 2629 mental disorder cases reported in Karnali Academy of health Science. 578 (61.22\%) were females and 366 (38.77\%) were males in first year and 1009 (40.11\%) were females and 676 (59.89\%) were males in the second year. Mental disorder was more among females than in male in both years. Most commonly occurred mental disorder was anxiety, depression, somatoform disorder, alcohol dependence disorder, bipolar affective mood disorder and psychosis. Of all the cases, most of commonly occurring case was mood disorders. Conclusion: Mental illness is seen in increasing trend so that the existing health service facilities must be given attention and priorities. More study is needed to find the contributing factors of mental illness among the female community. Attention and care will be the solution for improving the condition of the mental disorders. These findings can be utilized for planning the National Mental Health programme.
\end{abstract}

\section{Subject Areas}

Medical/Nursing Science 


\section{Keywords}

Anxiety Disorder, Mental Disorder, Outpatient Department, Mood Disorder, Counseling

\section{Introduction}

Mental illnesses are health conditions involving changes in emotion, thinking or behavior (or a combination of these). Mental illnesses are associated with distress and/or problems functioning in social, work or family activities. Mental illness is common. In a given year 2018, nearly one in five (19 percent) U.S. adults experience some form of mental illness; one in 24 (4.1 percent) has a serious mental illness; one in 12 (8.5 percent) has a diagnosable substance use disorder [1].

The mental and behavioral disorders account for about $12 \%$ of the global burden of disease. However, these estimates and projections are based largely on literature review rather than cross-national epidemiological surveys [2]. This shows that mental disorder is a global burden of disease.

First epidemiological field survey conducted in Kathmandu valley in 1984 estimated that the prevalence of mental illness around 14\%. Multi-sectorial action plan for the prevention and control of non-communicable disease (2014-2020) estimated $14 \%$ of non communicable disease burden is due to mental illness [3]. Another study also shows that in Nepal, most of the people think that suffering from mental illness is the same being mad becoming unfit to remain in society and the family due to loss of control over self or even possessed by a holy spirit or a black magic even patient with neurotic disorder does not like to consult mental health experts because of the stigma of the mental disease [4]. In 2017, 197.3 million (95\% UI 178.4 - 216.4) people had mental disorders in India, including 45.7 million $(42.4$ - 49.8) with depressive disorders and 44.9 million (41.2 - 48.9) with anxiety disorders. We found a significant, but modest, correlation between the prevalence of depressive disorders and suicide death rate at the state level for females $\left(\mathrm{r}^{2}=0.33, \mathrm{p}=0.0009\right)$ and males $\left(\mathrm{r}^{2}=0.19, \mathrm{p}=0.015\right)$ [5].

The research in Japan showed that over $80 \%$ of the participants of the age group 18 - 64 believed that depressive disorder or schizophrenia could be cure via treatment. However, Japanese people still had relatively strong vigilance and denial of competency towards schizophrenia [6]. From this, we can understand people believe that mental illness is curable.

The study in China shows that 552 respondents completed the survey between July 22, 2013, and March 5, 2015. The weighted prevalence of any disorder (excluding dementia) was $9.3 \%$ (95\% CI 5.4 - 13.3) during the 12 months before the interview and $16.6 \%(13.0$ - 20.2) during the participants' entire lifetime before the interview. Anxiety disorders were the most common class of disorders both in the 12 months before the interview (weighted prevalence 5.0\%, $4.2-5.8$ ) and 
in lifetime $(7.6 \%, 6.3-8.8)$. The weighted prevalence of dementia in people aged 65 years or older was $5.6 \%$ (3.5 - 7.6) [7].

A lifetime mental disorder was found among more than one-third of respondents in five countries (Colombia, France, New Zealand, Ukraine, United States), more than one-fourth in six countries (Belgium, Germany, Lebanon, Mexico, Netherlands, South Africa), and more than one-sixth in other four (Israel, Italy, Japan, Spain). The remaining two countries, China (13.2\%) and Nigeria (12.0\%), had considerably lower prevalence estimates that are likely to be downwardly biased [8]. It shows that mental disorder is common in most of the countries so as mental disorder in found in Nepal. This study was carried out to examine the pattern of the mental problems of patients attending the mental health clinic of KAHS; the main objective of the study is to find the pattern of mental health problems of Karnali province mental disorders among the patient attending psychiatric OPD in Karnali Academy of Health Sciences, Jumla were in included.

\section{Materials and Methods}

This retrospective study includes patients who visited Psychiatric OPD (Out Patient Department) of Karnali Academy of Health Sciences Teaching Hospital (KAHSTH), Jumla Nepal. It is a tertiary level 300 bedded hospital situated in high hilly region of Karnali Province, Jumla Nepal. The study was during the period of two year from April 1, 2018 to march 30, 2020. The record of patient attending the psychiatric OPD were obtained from psychiatric OPD record book. The record files were obtained from hospital record section from the registers maintained at the medical records department of KAHS. All respondents having mental disorder were included and others were excluded from the study. Data were entered into the MS excel and analyzed in SPSS version 15. Descriptive analysis was carried out. Ethical was taken from the Intuitional Review committee of Karnali Academy of Health Science.

\section{Study Design}

It is a retrospective study design. The study conducted among patients those who visited OPD with mental disorders from April 12018 to March 302020. The study conducted in Karnali Academy of Health Sciences in Jumla district. The study population consists of all patients visited OPD due to mental disorders during the mention date. Data collected from the registers maintained in the medical records department.

\section{Results}

The total number patient visited OPD of Karnali Academy of Health science in two year was 98,434. Out of these 2629 were mental disorder cases reported in the hospital by psychiatrist. In first year total cases were 944 where as in second year total psychiatric cases were 1685 . 
Figure 1 shows that the Patients attending psychiatric OPD were lowest in the month of April 26 (2.75\%) and highest in the month July 125 (13.24\%).

Figure 2 reveals that Patients attending psychiatric OPD were lowest in the month of October 112 (6.65\%) and highest in the month August 191 (11.34\%).

Figure 3 indices that of the total cases, 578 (61.22\%) were females and 366 (38.77\%)

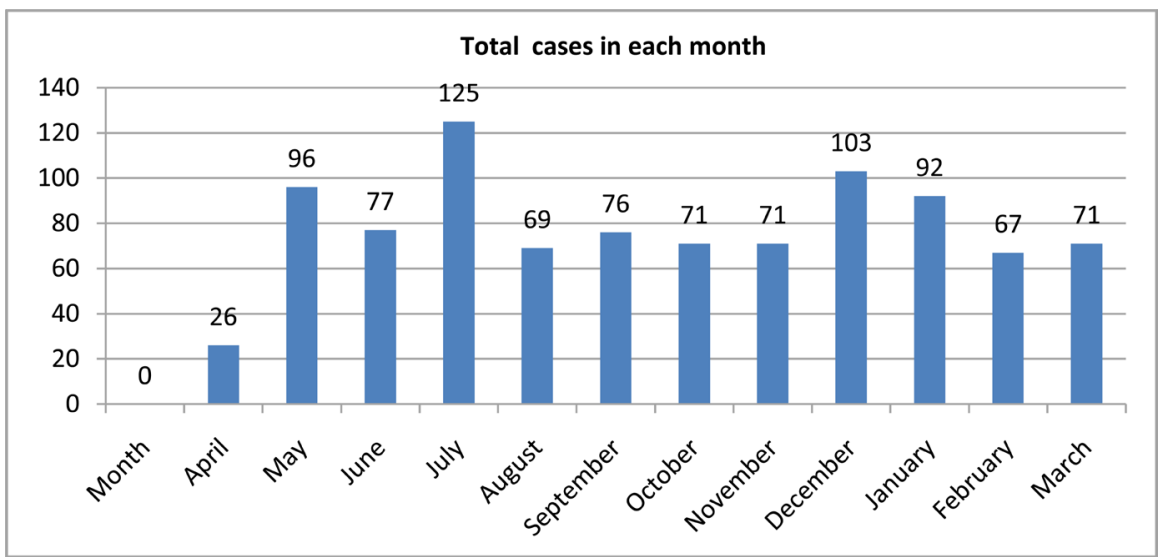

Figure 1. Patient receiving mental health service in each month in first year $(\mathrm{N}=944)$.

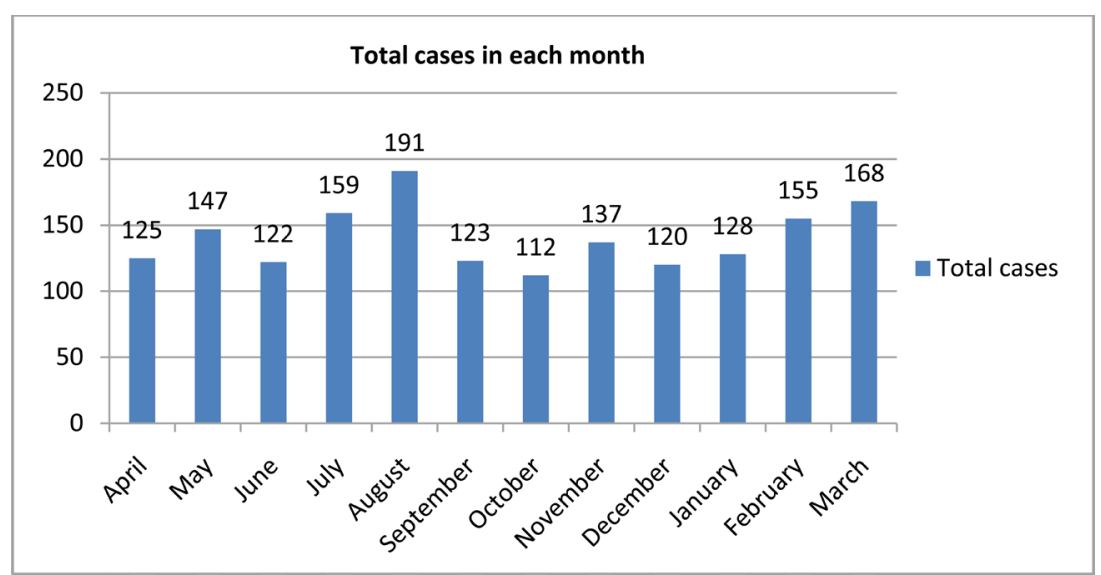

Figure 2. Patient receiving mental health service in each month in second year $(\mathrm{N}=1685)$.

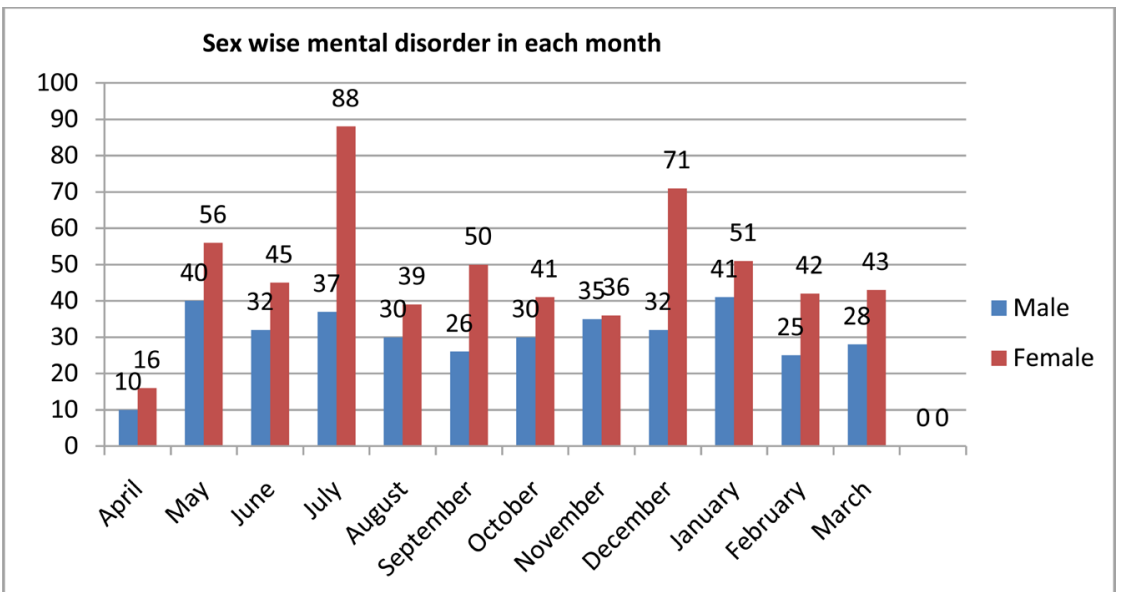

Figure 3. Trend of sex wise mental disorder in each month $(\mathrm{N}=944)$ in first year. 
were males. Mental disorder was more in females than males in each month.

Figure 4 indices that of the total cases, 1009 (40.11\%) were females and 676 (59.89\%) were males. Mental disorder was more in females than males in each month.

Table 1 shows that the pattern of disease found in Karnali Academy of Health Science that is seen maximum is anxiety disorder 726 (27.615\%) and minimum is $4(0.15 \%)$ others.

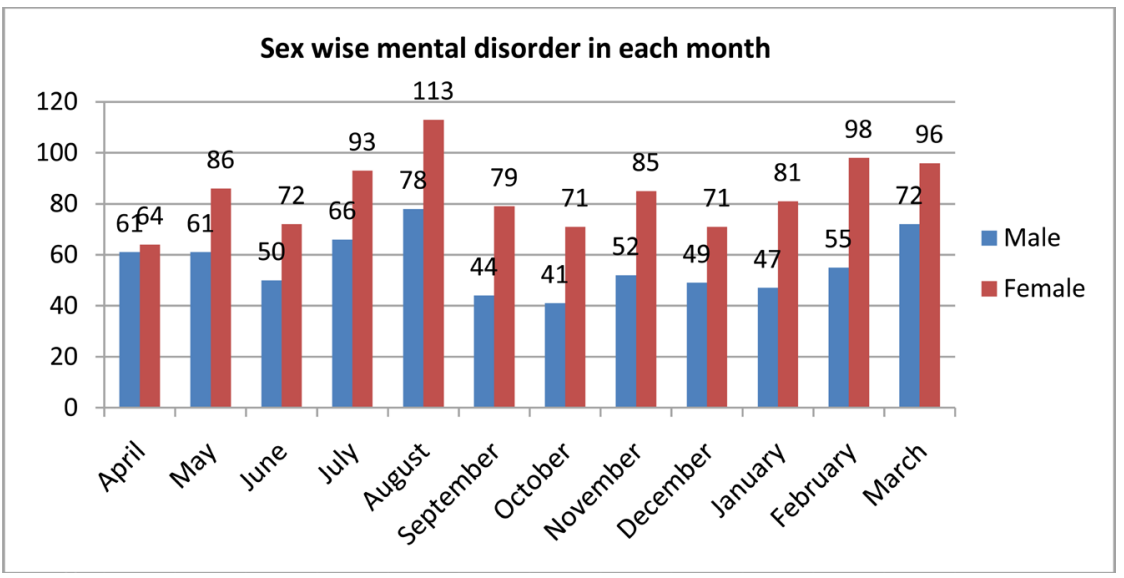

Figure 4. Trend of sex wise mental disorder in each month $(\mathrm{N}=1685)$ in second year.

Table 1. Pattern of mental disorder cases of patients visiting OPD in KAHS 2018 April 1 to 2020 March 30 .

\begin{tabular}{ccc}
\hline Diagnosis & Frequency & Percentages (\%) \\
\hline Anxiety disorder & 726 & 27.615 \\
Depression & 411 & 15.633 \\
Somatoform Disorder & 285 & 10.840 \\
BPAD & 192 & 7.303 \\
Alcohol dependence syndrome & 179 & 6.808 \\
Mania & 143 & 5.439 \\
Psychosis & 187 & 7.112 \\
Insomnia & 173 & 6.580 \\
Conversion disorder & 116 & 4.412 \\
Schizophrenia & 99 & 3.765 \\
Posttraumatic stress disorder & 87 & 3.309 \\
Mental retardation & 10 & 0.380 \\
Typerthyroidism with anxiety & 9 & 0.342 \\
Postpartum disorder & 8629 & 0.304 \\
Others & 4 & 9.1521 \\
Total & & \\
\hline
\end{tabular}




\section{Discussion}

In this study we found that out of 43,490 total OPD cases $6.04 \%$ of the participants had any current mental disorder which was $2.17 \%$ in first year and $3.87 \%$ in second year. Highest prevalence was found among female $61.22 \%$ than the male $38.77 \%$.

In the world, most of the countries report more than one in three people suffering at least one type of mental disorders in their life [5]. In the developing countries, psychiatric morbidity range from $40 \%$ to $75 \%$ [9].

In the Alonso et al., study anxiety disorders were 13.6\% [10]'Anxiety disorders frequently co-occur with depressive disorders or substance abuse [11] Females have higher rates of anxiety disorders [12]. Rate of anxiety varies between $16 \%$ and $45 \%$ [13]. In the present study mental disorder is more in female $(61.22 \%)$ as compare to male (38.77). The possible causes that aggravate female rather than male for the mental disorder may be as patriarchal society of Nepal, due to violence and abuse, relationship with husband high rate of male migration.

A review of anxiety disorder surveys in different countries found average lifetime prevalence estimates of $16.6 \%$, with women having higher rates on average [14]. An ongoing survey indicates that anxiety disorder is the most common mental disorder [14]. As similar result found in the present study as 419 (44.385\%) were suffering from anxiety disorder.

Fourteen per cent reported a lifetime history of any mood disorder, 13.6\% any anxiety disorder and 5.2\% a lifetime history of any alcohol disorder. More than $6 \%$ reported anxiety disorder, $4.2 \%$ mood disorder, and $1.0 \%$ any alcohol disorder in the last year. Major depression and specific phobia were the most common single mental disorders. Women were twice as likely to suffer 12-month mood and anxiety disorders as men, while men were more likely to suffer alcohol abuse disorders [12]. As the present study shows that mental and behavioral disorders are due to anxiety $726(27.615 \%)$, depression 411 (15.633\%) and alcohol dependence syndrome 179 (10.840\%).

Health Authority figures showed that $10 \%$ of the state's population suffers from psychiatric disorders, $2 \%$ have severe psychiatric disorders such as schizophrenia and manic depression, $2 \%$ - 3\% suffers psychosomatic disorders and neurosis and one in every 100 kids below 6 years of age is mentally retarded [9]. The present study shows that depression (15.633\%) somatoform disorder 285 (10.84\%) and Psychosis 187 (7.112\%) and 8 (0.30\%) postpartum disorder

\section{Limitation of the Study}

The study is a retrospective study so it is a limitation. The different variables that the researcher wants to measure that may not be measurable due to unavailability of the data that are recorded in the register. As in future day's prospective study is needed to be done in the related subject matter.

Using such limited resources findings may not be fit for generalization. Limited time and resources may not supplement the ideas. Even though based on 
formal data of the mental disorder, it shows the baseline data for the further planning and change in the modalities of treatment.

\section{Conclusions}

Mental disorders are increasing in every month. The present study elaborates different types of mental disorders in both sexes. Mental disorder is more common in females than in males. So health education to the community is essential in Jumla for the prevention of mental disorders. And attention and care to the female is also essential for the prevention of mental disorder. Further study regarding the contributing factors of mental illness among female is also essential in the context of Jumla.

Educational institutions and workplace can be a very important catchment area to address mental health issues. Formation child friendly school, inclusion of programs that supports children to speak about stresses, failures and pressures at school level, anti-bullying programs, awareness on drugs and anti-drug programs, provision of counseling sessions for students and training teachers on identifying symptoms and necessary skills to handle such issue at primary level are some of the possible interventions that will create supportive environment against mental health. Moreover, stress prevention program at work settings, provision of physical exercise at work and home settings will help to reduce mental stressors. Physical activity also helps to improve mental health. Developing skills to disclose any problems they have and the problem they are going through in life is equally important. The prevention of mental illnesses should be looked through a primary prevention approach so that the risk factors and their precipitators for poor mental health outcomes at the different levels of community and social structures can be mitigated.

\section{Conflicts of Interest}

The authors declare no conflicts of interest regarding the publication of this paper.

\section{References}

[1] Parekh, R. (2018) World Health Organization World Health Report August 2018.

[2] Deswal, B.S. and Pawar, A. (2012) An Epidemiological Study of Mental Disorders at Pune, Maharashtra. Indian Journal of Community Medicine, 37, 116-121. https://doi.org/10.4103/0970-0218.96097

[3] National Health Research Council Gov. of Nepal Health Research Council, National Mental Health Survey.

[4] Devkota, M. (2012) APA Psychology International 15 July 2011 Psychology in Action Mental Health in Nepal: The Voice of Koshish. https://doi.org/10.1037/e519282012-005

[5] RSA and RD (2019) The Lancet Psychiatry the Burden of Mental Disorders across the State of India the Global Burden of Disease Study 2019 LD.

[6] Kasachara, M., Matoba, T., Killuzawa, S., et al. (2018) Public Perception towards 
Mental Illness in Japan. Asian Journal of Psychiatric, 35, 55-60. https://doi.org/10.1016/j.ajp.2018.05.021

[7] Huang, Y.G., Wang, Y., Wang, H., et al. (2019) Prevalence of Mental Disorders in China: A Cross-Sectional Epidemiological Study. The Lancet Psychiatry, 6, 211-224. https://doi.org/10.1016/S2215-0366(19)30177-4

[8] Alonso, J. (2017) A Study on Mental Disorder.

[9] Radhakrishnan, M.G. (2011) Kerala's Mental Block, Mental Illness, Alcoholism, Domestic Violence Takes a Toll on Kerala. Indian Today.

[10] Mental Disorders. https://en.wikipedia.org/wiki/Mental_disorder

[11] WHO International Consortium in Psychiatric Epidemiology (2000) Cross-National Comparisons of the Prevalences and Correlates of Mental Disorders/WHO International Consortium in Psychiatric Epidemiology. Bulletin of the World Health Organization: The International Journal of Public Health, 78, 413-426.

[12] Alonso, J., Angermeyer, M.C., Bernert, S., Bruffaerts, R., Brugha, T.S. and Bryson, H. (2004) Prevalence of Mental Disorders in Europe: Results from the European Study of the Epidemiology of Mental Disorders (ESEMeD) Project. Acta Psychiatrica Scandinavica, 109, 21-27.

[13] Betheda, M.D. (2005) National Institute of Mental Health. Mental Illness Exacts Heavy Toll, Beginning in Youth.

[14] Demyttenaere, K., Bruffaerts, R., Posada-Villa, J., Gasquet, I., Kovess, V., Lepine, J.P., et al. (2004) WHO World Mental Health Survey Consortium. Prevalence, Severity and Unmet Need for Treatment of Mental Disorders in the World Health Organisation World Mental Health Surveys. JAMA, 291, 2581-2590. 